\begin{tabular}{c} 
Brazilian Journal \\
of Chemical \\
Engineering \\
\hline
\end{tabular}

ISSN 0104-6632

Printed in Brazil

www.abeq.org.br/bjche

Vol. 32, No. 04, pp. 857 - 864, October - December, 2015

dx.doi.org/10.1590/0104-6632.20150324s00003008

\title{
HYDRODYNAMICS OF PLATE COLUMN FOR ENZYMATIC REACTIONS OF OIL
}

\author{
A. Dondge and V. K. Rathod* \\ Chemical Engineering Department, Institute of Chemical Technology, \\ Matunga, Mumbai-40019, India. \\ Phone: 91-22-33612020, Fax: 91-22-33611020 \\ E-mail: vk.rathod@ictmumbai.edu.in
}

(Submitted: October 2, 2013 ; Revised: September 17, 2014 ; Accepted: October 2, 2014)

\begin{abstract}
This work describes the hydrodynamics of a plate column of $5 \mathrm{~cm}$ inner diameter and $2.75 \mathrm{~m}$ height, operated in a semi-batch manner using an oil-water system especially important for enzymatic catalyzed reactions. The parameters such as dispersed phase superficial velocity, plate orifice size, number of nozzles, nozzle size and plate spacing, affecting the dispersed phase hold up, were investigated. It was observed that the orifice plate produced an uneven change in drop diameter and hence nozzles were used to study the hydrodynamics. The total and dynamic hold ups determined were increased with an increase in dispersed phase superficial velocity, while decreased with an increase in a nozzle size. The total hold up decreased, while dynamic hold up slightly increased with an increase in plate spacing. Correlations obtained are found to be appropriate for the estimation of the total hold up and dynamic hold up.

Keywords: Plate column; Hydrodynamics; Hold up; Oil-water system; Enzymatic reactions.
\end{abstract}

\section{INTRODUCTION}

The current industrial enzymatic processes are usually carried out in a batch reactor, which suffers from various well documented limitations. Although various reactions such as hydrolysis, esterification, transesterification etc. can be catalyzed using acid/ alkali, the use of enzyme as a catalyst has several advantages, including being an environmentally friendly process and mild reaction conditions (Brady et al., 1988; Kimura et al., 1983; Posorske et al., 1988; Van et al., 1992). This enzyme catalytic process is very important when the substrate used is highly heat sensitive like castor oil. Hydrolysis is one of the important reactions as the products of hydrolysis, i.e., fatty acids, have various applications in industries. Since enzymatic reactions are very slow, taking longer time for completion of the reaction, batch reactors are not recommended for enzymatic hydrolysis of oil (Puthli et al., 2006). Further, it is also re- ported that the continuous removal of fatty acid from the reaction mixture helps in enhancing the rate of enzyme-catalyzed reaction. During an attempt to carry out the enzyme-catalyzed reaction using castor oil as a substrate in a spray column, it was found that coalescence at the top of column also played an important role in the reaction (Rathod and Pandit, 2012). Since a plate column provides repeated coalescence and redispersion of drops and reduces the back mixing, it was selected for the current study. The sieve plates column consists of multiorifice plates with or without down comers. The plates reduce the extent of back mixing of the continuous phase. A sieve plate column can be considered as a series of short and wide spray column sections or stages arranged one over the other in which the contacting phases flow counter currently between the stages. The application of plate columns for liquidliquid extraction has been reported in the literature and a number of papers are available. However, there

*To whom correspondence should be addressed 
is no research paper available mentioning the use of plate columns for enzyme-catalyzed reactions.

The enzyme-catalyzed reactions are interfacial reactions and the generation of large interfacial area is very important in any reactor. The interfacial area in a plate column depends on the dispersed phase hold up and drop sizes which further depend on various geometrical and operating parameters. Most of the work reported on the sieve plate column is dedicated to conventional liquid-liquid extraction or aqueous two-phase extraction systems (Igarshi et al., 2004; Hamidi et al., 1999; Bhawsar et al., 1994; Muthuravichandran et al., 1990; Rathod and Pandit, 2009). However there is practically no information available in the literature on the hydrodynamics of a sieve/nozzle plate column for the system like castor oil-water, which has different physico-chemical properties as compared with conventional systems. With the available literature, it is difficult to design a column reactor for the enzyme-catalyzed reaction of oil. Thus, there is a need for a systematic study of the effect of design parameters on the hydrodynamic characteristics of the sieve plate column that can enable the scale up of this column, especially for enzymatic reactions. This paper describes the experimental study of the hydrodynamics of a sieve plate column using the castor oil-water system, followed by development of correlations for estimation of parameters.

\section{EXPERIMENTAL DETAILS}

\section{Materials}

The two phase system i.e. castor oil-water system was used. The castor oil was purchased from Ashwin Chemicals.

\section{Estimation of Physical Properties}

Phase densities were measured using a specific gravity bottle at room temperature $\left(30 \pm 2{ }^{\circ} \mathrm{C}\right)$, and viscosities were measured using a Brookfield viscometer. The interfacial tension of oil and water was measured using a Tensiometer (Kruss, Model No. K11), by Wilhelmy Ring method at room temperature $\left(30 \pm 2{ }^{\circ} \mathrm{C}\right)$ (Dondge and Rathod, 2012). Table 1 gives the physical properties of the phases used.

Table 1: Physical properties of system.

\begin{tabular}{|c|c|c|c|c|}
\hline \multicolumn{2}{|c|}{ Viscosity (Pas) } & \multicolumn{2}{|c|}{ Density $\left(\mathrm{kg} / \mathrm{m}^{3}\right)$} & \multirow{2}{*}{$\begin{array}{c}\text { Interfacial } \\
\text { Tension } \\
\text { (mN/m) }\end{array}$} \\
\hline Water & Castor oil & Water & Castor oil & \\
\hline 0.001 & 0.418 & 1000 & 942.5 & 8.2 \\
\hline
\end{tabular}

\section{Equipment}

The plate column used for the study consisted of an acrylic column having $5 \mathrm{~cm}$ inside diameter and $2.75 \mathrm{~m}$ height which was divided into five sections for sieve/nozzle plates and a distributor at the bottom. The sections were $50 \mathrm{~cm}$ in height. Every section had two flanges of $60 \mathrm{~mm}$ internal diameter and $120 \mathrm{~mm}$ outside diameter. Different nozzle plates were made from Acrylic with $120 \mathrm{~mm}$ diameter having 7, 14 and 19 nozzles of $0.65 \mathrm{~mm}, 1.0 \mathrm{~mm}, 1.5 \mathrm{~mm}$ diameters and uniform height, arranged on a triangular pitch. A schematic diagram of the plate column, and the top views of sieve/nozzle plates are shown in Figure 1 and Figure 2 respectively. Table 2 gives the design details of the nozzle plates. To study the effect of column parameters on the total hold-up and dynamic hold-up, the clear continuous phase height in the column was kept at $2.5 \mathrm{~m}$. Further, the relation between drop size and terminal rise velocity was studied using the same column without plates (Dhondge and Rathod, 2012), keeping the height of clear continuous phase at $2.5 \mathrm{~m}$ above the nozzle tips.

\section{Experimental Procedure}

All experiments were performed using water as continuous phase and castor oil as the dispersed phase. The sieve-plate column was operated in a semi-batch manner where oil is continuously passed through the continuous phase, which was in the batch mode. The castor oil was continuously dispersed at known flow rate from the bottom of the column using a peristaltic pump and droplets were formed through repeated coalescence and redispersion due to the presence of the sieve plates. The lighter phase oil droplets coalesced at the top of the heavier phase and the coalesced layer was removed through the overflow outlet. The continuous phase was filled in the sieve-plate column by peristaltic pump until the desired clear continuous phase height in the column was achieved. In order to ensure the steady state with respect to dispersion characteristics, the dispersed phase was continuously pumped for a period which was always greater than 10 times the residence time of the dispersed phase. Various experiments were performed using the above procedure and the parameters such as type of plate, superficial dispersed phase velocity, plate spacing, number and size of nozzle, affecting the total and dynamic holdup, had been studied in detail. Initially, a few experiments were carried out using sieve plates and further experiments were performed with nozzle plates. 


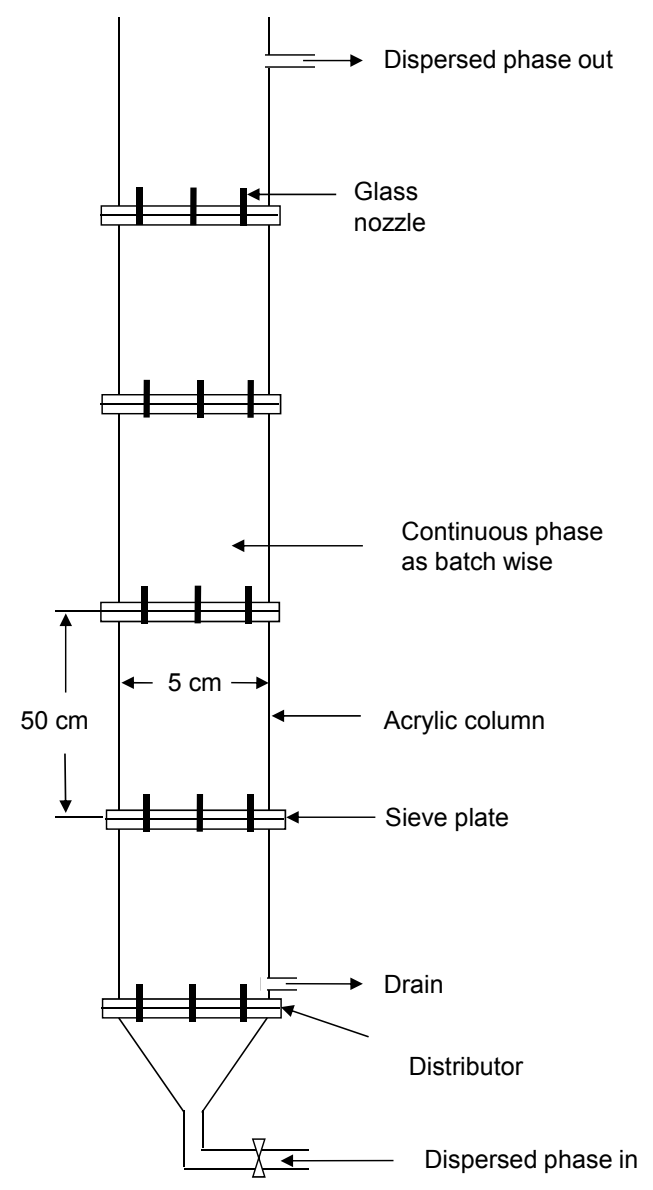

Figure 1: Schematic diagram of sieve plate column.

Table 2: Details of plate column design, material of construction: $120 \mathrm{~mm}$ diameter with glass nozzles, $H_{c}=2.75 \mathrm{~m}$.

\begin{tabular}{|c|c|c|c|c|}
\hline Sr. No & $\begin{array}{c}\text { Number of } \\
\text { nozzles, } \\
\mathbf{N}\end{array}$ & $\begin{array}{c}\text { Nozzle size, } \\
\mathbf{d}_{\mathbf{n}}(\mathbf{m m})\end{array}$ & $\begin{array}{c}\text { Plate } \\
\text { spacing, } \mathbf{Z} \\
\mathbf{( m )}\end{array}$ & $\begin{array}{c}\text { Number of } \\
\text { plates }\end{array}$ \\
\hline 1 & 7 & 1 & 2 & 1 \\
2 & 7 & 1 & 1 & 2 \\
3 & 7 & 1 & 0.5 & 4 \\
4 & 7 & 1.5 & 0.5 & 4 \\
5 & 7 & 0.65 & 0.5 & 4 \\
6 & 14 & 0.65 & 0.5 & 4 \\
7 & 19 & 0.65 & 0.5 & 4 \\
\hline
\end{tabular}

\section{Hold up Measurement}

In the sieve plate column, the dispersed phase distributes as drops which move through continuous phase till next plate and accumulates below the plate due to plate resistance. The accumulated drops coalesce and a layer of oil below each plate is formed. Thus, based on the dispersed phase distribution, the
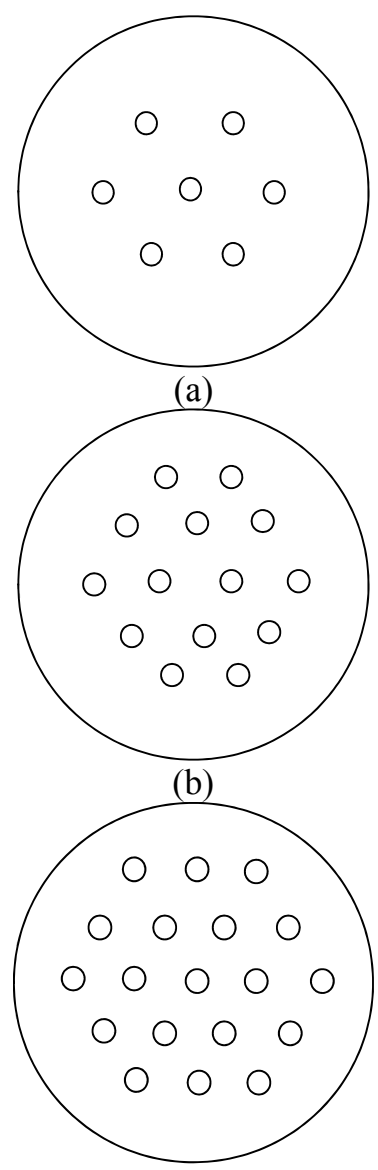

(c)

Figure 2: Details of plates: (a) 7 nozzles, (b) 14 nozzles, (c) 19 nozzles; $d_{n}=0.65 \mathrm{~mm}$.

dispersed phase hold up is divided in two, i.e., dynamic hold up and static holdup. Dynamic hold up is the ratio of the dispersed volume to the total volume and the ratio of the volume of coalesced layer to the total volume is termed as the static hold-up. The total hold-up is given by the sum of dynamic and static hold-ups. Static hold up contributes significantly towards mass transfer, as reported earlier (Rathod and Pandit, 2012), as well as helps in deciding the minimum amount of dispersed phase required to operate the column and height of the column. Further, dynamic hold up requires to determine the interfacial area of contact between the dispersed phase droplets and the continuous phase. The dynamic hold-up, the total hold-up and the static hold-up were determined by the procedure suggested by Bhawsar et al., (1994) from the following equations:

$$
\varepsilon_{t}=\frac{\left(H_{d}-H\right)}{H_{d}}
$$


$\varepsilon_{d}=\frac{\left(H_{d}-H-\sum_{i}^{4} h_{i}\right)}{H_{d}}$

$\varepsilon_{s}=\frac{\sum_{i}^{4} h_{i}}{H_{d}}$

\section{Drop Size in Sieve Plate Column}

Interfacial area also depended on the drop size of the dispersed phase and, in the present work, the drop size and terminal rise velocity were obtained from the single drop experiment as described earlier (Dondge \& Rathod, 2012). These results were used to estimate the drop size in the sieve plate column.

\section{RESULTS AND DISCUSSION}

\section{Drop Size}

It is well known that the size and velocity of the drops are important as it decides the performance of a sieve plate column. Although various correlations are available for the drop size and the terminal rise velocity of the drops in the literature, they cannot be used for the present range of phiysical properties. Therefore, the data reported earlier for single drop experiments was used for determining the average drop size in the sieve plate column (Dondge and Rathod, 2012). The relation between the drop size and terminal rise velocity, obtained from the single drop experiment, is depicted in Figure 3.

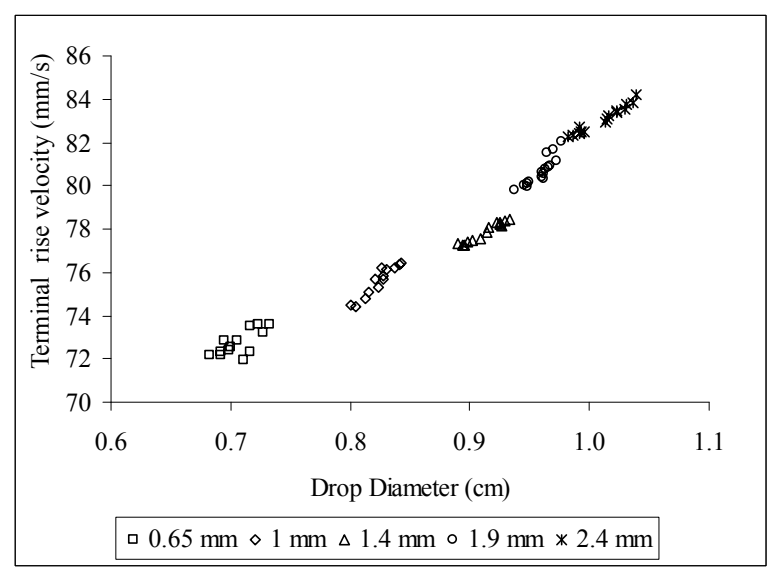

Figure 3: Variation of terminal rise velocity with drop diameter.
In the diameter range studied, an increase in the drop diameter resulted in a linear increase in the terminal rise velocity. This is because the steady-state terminal rise velocity of the single drops (occur when the buoyant force is equal to the sum of drag force on the drops and weight) varies with the drop diameter. Similar results are also reported in the literature (Bhawsar et al., 1996).

\section{Effect of Plate Orifice Size}

The effect of an orifice on the drop diameter was studied for two different orifices of size $1 \mathrm{~mm}$ and $1.5 \mathrm{~mm}$ on the plates. This effect was investigated in detail by making a single orifice on each plate for various superficial dispersed phase velocities. The sieve plate column consisted of four plates with a single orifice of desired size and a distributor plate with nozzle of the same size as an orifice. It was observed that, at a particular superficial velocity of dispersed phase $(0.16 \mathrm{~mm} / \mathrm{s})$, the drop formed due to an orifice became uncontrollably large (nearly double) as compared to the nozzle of the same size. The drop sizes obtained with an orifice of size $1 \mathrm{~mm}$ were $1.61,1.74,1.77$ and $1.55 \mathrm{~cm}$ and $1.77,1.51,1.73$ and $1.61 \mathrm{~cm}$ for an orifice of size $1.5 \mathrm{~mm}$ from the first, second, third and fourth plate from the bottom, respectively, whereas the drop sizes obtained with distributor nozzle sizes of 1 and $1.5 \mathrm{~mm}$ were 0.82 and $0.87 \mathrm{~mm}$, respectively, for the superficial dispersed phase velocity of $0.16 \mathrm{~mm} / \mathrm{s}$. This uneven change in the drop size with respect to the plate position is shown in Figure 4 and Figure 5. This is probably due to the preferential wetting of the material of the plate by the dispersed phase liquid that results in formation of large size globules.

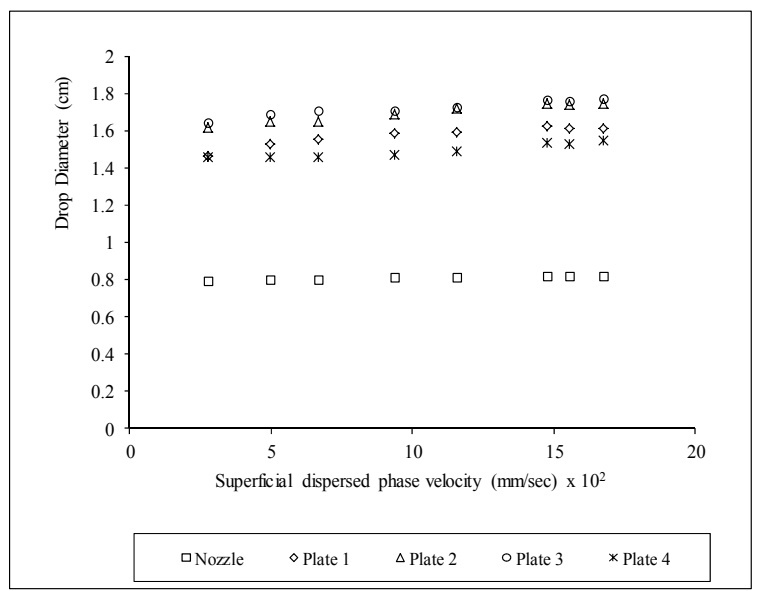

Figure 4: Effect of orifice on the drop diameter for nozzle size of $1 \mathrm{~mm}$. 


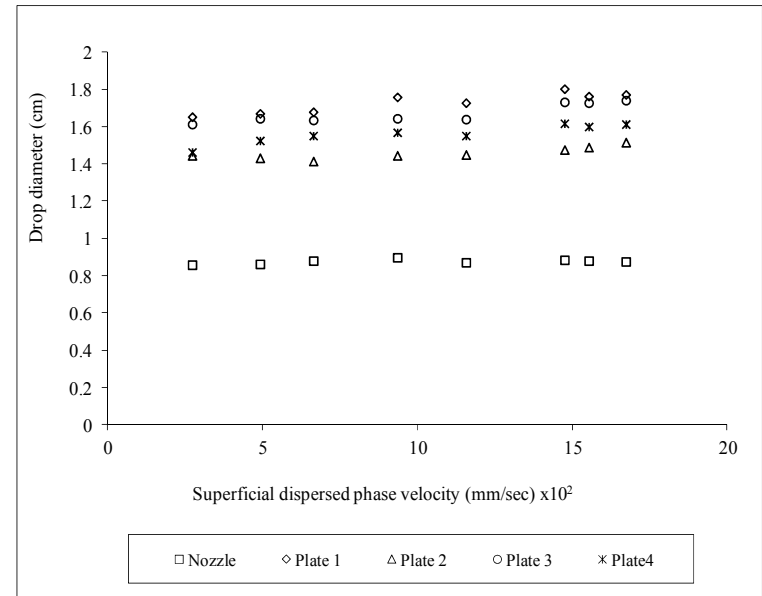

Figure 5: Effect of orifice on the drop diameter for nozzle size of $1.5 \mathrm{~mm}$.

An increased in drop diameter resulted in a decrease in dispersed phase hold up and the interfacial area, which further affects the performance of the column. This problem can be corrected or minimized by using nozzles in place of orifices in the plates. Thus, in order to have a proper control and smaller size of the drop, nozzles were used for the further study. This was also suggested by Treybal (1980) and Mayfield and Church (1952).

\section{Effect of Superficial Dispersed Phase Velocity}

In order to study the effect of the superficial dispersed phase velocity, it was varied in the range of $0.04-0.21 \mathrm{~mm} / \mathrm{s}$. The result obtained for the effect of superficial velocity with various plate spacings, nozzles sizes and numbers of nozzle are shown in Figures 6, 7 and 8, respectively. In all these experiments, it is found that an increase in superficial dispersed phase velocity resulted in an increase in the total hold-up, as well as the dispersed phase dynamic hold-up. The frequency of drop formation increased with an increase in dispersed phase velocity in the single drop experiments. A marginal change in the drop size was observed with an increase in the superficial velocity, which results in a marginal increase in a terminal rise velocity of the drop. Due to the marginal change in terminal rise velocity, the number of drops of the dispersed phase in the same volume of the continuous phase increased with the dispersed phase superficial velocity. This resulted in an increase in the dispersed phase hold up for higher values of dispersed phase velocities. Similar trends have been reported earlier in a spray column of $2.5 \mathrm{~cm}$ diameter for a castor oil-water system (Dondge and Rathod, 2012).

\section{Effect of Plate Spacing}

The effect of the plate spacing was investigated in the $5 \mathrm{~cm}$ internal diameter column by keeping the number of nozzles (7) and their size (1 mm) constant. The plate spacing was varied from $200 \mathrm{~cm}$ to $50 \mathrm{~cm}$ by varying the number of plates from one to four. Figure 6 shows the effect of plate spacing on the total hold up and the dispersed phase dynamic hold-up. It was found that the fractional dispersed phase dynamic holdup decreased slightly, while the total hold-up increased with the decrease in plate spacing (i.e., increase in the number of plates). An increase in the number of plates in a column with the same column height resulted in a decrease in the plate spacing. This also gave more coalescence and redispersion of the dispersed phase droplets and a greater total volume of coalesced layer below the plates. This was the reason for the increase in the total holdup with a decrease in plate spacing. The dispersed phase droplets detached away from the tip of the nozzle and the use of a nozzle decreased the effective clear liquid height. Therefore, an increase in the number of plates reduced the height for the travel of drops before coalescence, which led to a slight decrease in dispersed phase dynamic hold-up. These results are well supported by earlier reported work (Lodh and Rao, 1966; Krishnamurty and Rao, 1968; Rocha et al., 1986).

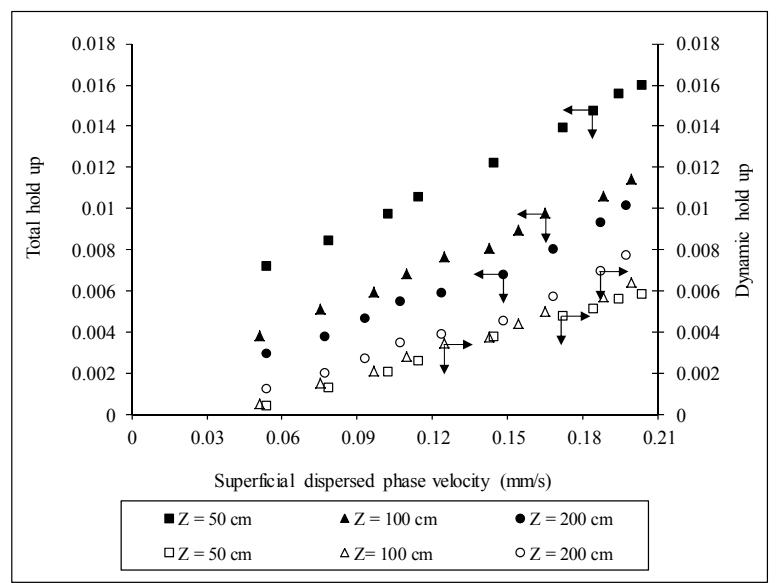

Figure 6: Effect of plate spacing on the hold up for different superficial dispersed phase velocities.

\section{Effect of Nozzle Size}

The diameter of the nozzle (fixed on the distributer plates) determined the size of the drop formed at the tip of the nozzle and hence one of the important parameters in designing of the sieve plate column. Here, the effect of nozzle size was studied for a dis- 
tributor plate and the four plate configurations with 7 nozzles on each plate in the same column of $5 \mathrm{~cm}$ diameter. The plates with nozzle sizes varying from $0.65 \mathrm{~mm}$ to $1.5 \mathrm{~mm}$ internal diameter were used. The effect of nozzle size on the total hold-up, $\varepsilon_{t}$, and the fractional dispersed phase hold-up (dynamic hold up), $\varepsilon_{d}$, was studied and the results of the experiments are presented in Figure 7.

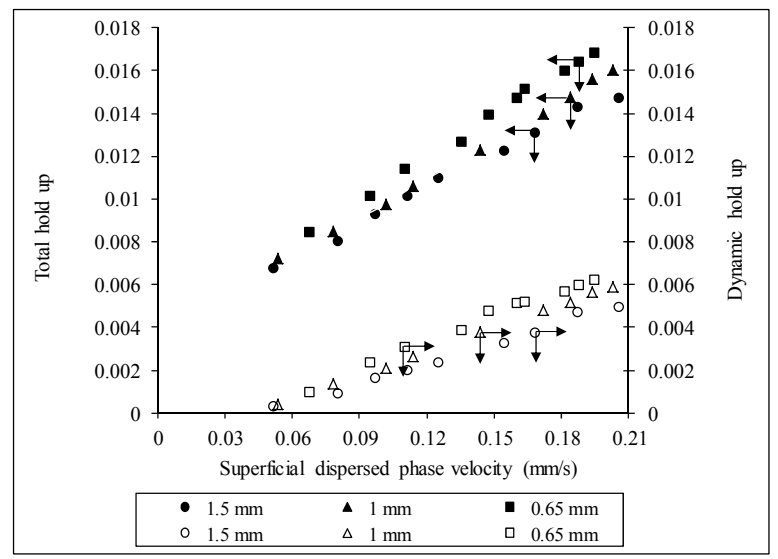

Figure 7: Effect of nozzle size on the hold up for different superficial dispersed phase velocities.

As expected it was observed that a decrease in nozzle size from $1.5 \mathrm{~cm}$ to $0.65 \mathrm{~mm}$ resulted in an increase in both of the hold-ups for a given dispersed phase velocity. An increase in nozzle size increased the drop size, which led to an increase in the rise velocity. Further, at a particular superficial velocity, the number of drops formed with a bigger nozzle also decreased and thus the dynamic hold up decreased. Similarly, an increase in nozzle size increased the cross flow area which reduced resistance to flow of the dispersed phase through it. Therefore, lower hydrostatic head was required to pass the dispersed phase through the nozzle, i.e., less static layer height. This results in the decrease in dispersed phase static hold up and ultimately the total hold up, as explained by Krishnamurthy et al. (1967). On the other hand, when nozzle size was increased for a constant number of nozzles, the cross sectional area of nozzles also increased, which resulted in requirement of higher superficial velocity to form a jet of the liquid. In other words, jetting velocity increased with an increase in nozzle size, which further led to an increased dispersed phase dynamic hold-up.

\section{Effect of Number of Nozzles}

Figure 8 shows the effect of the number of nozzles on the total hold-up and dispersed phase dynamic hold-up. The number of nozzles was varied from 7 to 19 keeping nozzle size constant $(0.65 \mathrm{~mm}$ internal diameter). Trends indicated that the values of both of the hold-ups increased with an increase in number of nozzles. Basically, the dispersed phase flowed through each nozzle in the form of a jet, which is dependent on the superficial velocity of the dispersed phase. The jet further gives drop which break and move upward through the continuous phase. The size of the drop decides the motion of the drop though the continuous phase. As the number of nozzles increased from 7 to 19 , the number of drops formed was higher due to more number of drop formation points. Since the jet length depends on the velocity of the liquid through the nozzle, an increase in the number of nozzles resulted in a decrease in nozzle velocity for the same superficial dispersed phase velocity. However, all the superficial velocities studied in this work were well below the jetting velocity and hence both the holdups increased with the number of nozzles. It was also observed that the measurement of continuous phase height was difficult for the higher number of nozzle. This was probably due to the increase in the number of drops at higher number of nozzle that led to a decrease in space and time for coalescence, which resulted in transfer of continuous phase along with dispersed phase in each section.

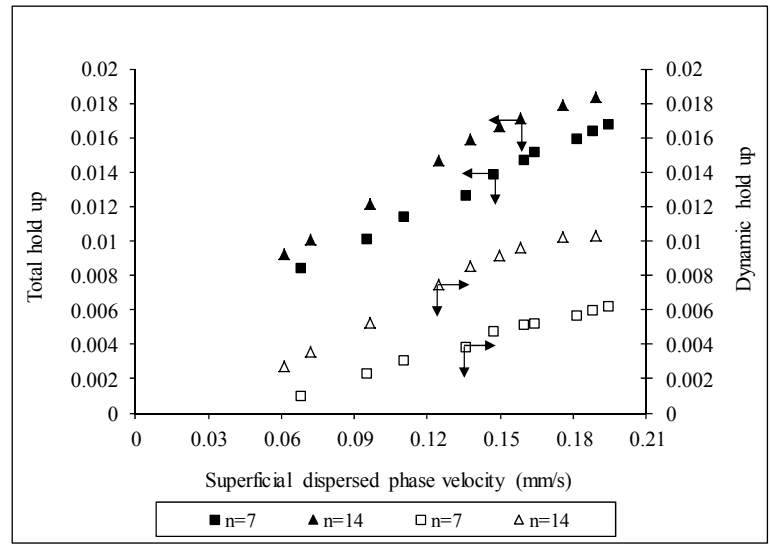

Figure 8: Effect of number of nozzles on the hold up for different superficial dispersed phase velocities.

\section{CORRELATIONS}

Experimental data obtained for the effect of design parameters (such as the number of nozzles, the nozzle size, the number of plates, and the plate spacing) on the total hold-up, $\varepsilon_{t}$, and the fractional dispersed phase hold-up, $\varepsilon_{d}$, was further used to develop correlations based on the dimensional numbers. Since this study highlighted the holdup, which is very important to determine the interfacial area, it was decided to elucidate the correlation between the hold-ups and the various design parameters. The following corre- 
lations were developed by nonlinear least square regression analysis for dispersed phase total hold up $\left(\varepsilon_{t}\right)$ and dispersed phase dynamic hold up $\left(\varepsilon_{d}\right)$.

$$
\begin{gathered}
\varepsilon_{t}=7.14 \times 10^{-4}(W e)^{0.5725}(F r)^{-0.218} \\
(M o)^{0.956}\left(d_{n} / Z\right)^{0.48}
\end{gathered}
$$

Standard deviation $=4.98 \%$

$$
\begin{gathered}
\varepsilon_{d}=7.61 \times 10^{-11}(\mathrm{We})^{1.929}(F r)^{-1.115} \\
(M o)^{2.684}\left(d_{n} / Z\right)^{-0.281}
\end{gathered}
$$

Standard deviation $=11.86 \%$

Parity plots are shown in Figures 9 and 10, which clearly show a good agreement of these correlations with the experimental data.

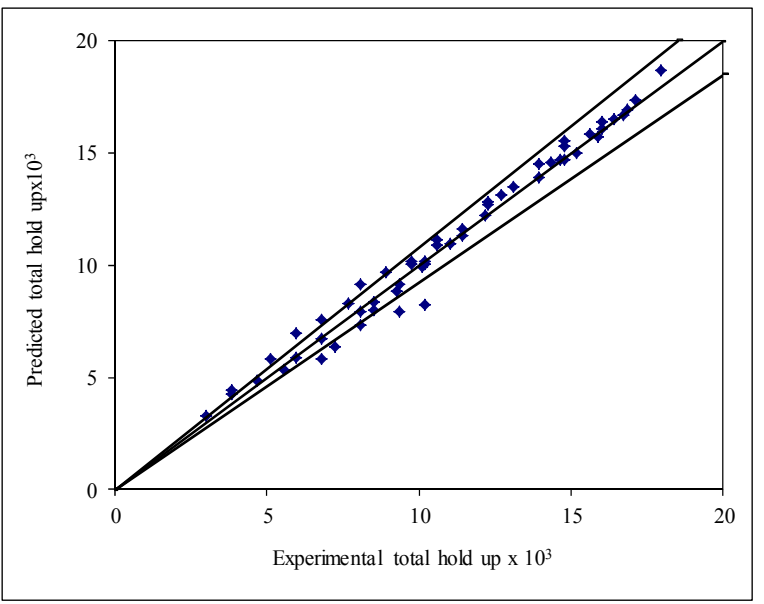

Figure 9: Parity plot of total hold up

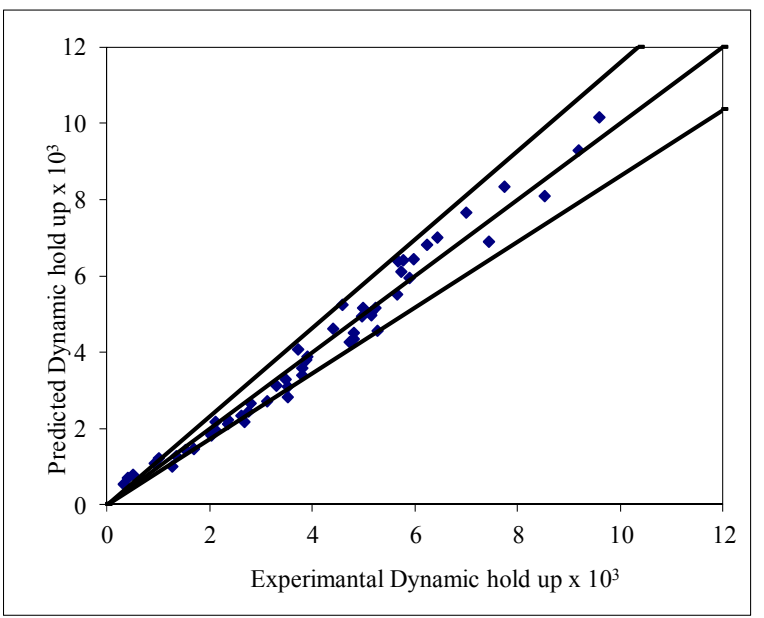

Figure 10: Parity plot of dynamic hold up

\section{CONCLUSIONS}

The effect of various parameters on hold up was successfully determined in a plate column for the system required for enzyme catalyzed reactions of oil. The type of plate, i.e., orifice or nozzle, had a significant effect on the size of the drop formed, which is higher for an orifice sieve plate as compared to a nozzle plate due to wetting. Therefore, it was recommended to use nozzles on the plate instead of orifices. The total hold-up and dynamic hold up increased with an increase in the superficial dispersed phase velocity in all the experiments, while decreased with an increase in the nozzle diameter. Total hold up increased while dynamic hold up slightly decreased with a reduction in plate spacing. The values of dispersed phase dynamic hold up and dispersed phase total hold up obtained by using the simplified models were compared with the experimental values and represented in parity plots. The models were found to be most appropriate for estimating these parameters. The experimental data and correlation obtained should be very useful in designing continuous sieve plate columns for enzyme-catalyzed hydrolysis reactions of oil.

\section{NOMENCLATURE}

$d_{n} \quad$ nozzle diameter $(\mathrm{m})$

$\mathrm{d}_{\mathrm{p}} \quad$ diameter of drop (m)

Fr Froude number $\left[\mathrm{u}_{\mathrm{n}}{ }^{2} /\left(\mathrm{d}_{\mathrm{n}} \mathrm{g}\right)\right]$

g acceleration due to gravity $\left(\mathrm{m} / \mathrm{s}^{2}\right)$

$H$ height of the clear continuous phase in the column (m)

$H_{D} \quad$ Height of dispersion (m)

$h \quad$ height of the static Layer (m)

$\mathrm{L} \quad$ wetted length $(\mathrm{m})$

Mo Morton number $\left[\mathrm{g} \Delta \rho \mu_{\mathrm{d}}^{4} /\left(\rho^{2} \sigma^{3}\right)\right]$

$\mathrm{N}$ number of nozzles

$\mathrm{u}_{\mathrm{n}} \quad$ nozzle velocity $(\mathrm{m} / \mathrm{s})$

$\mathrm{V}_{\infty}$ terminal rise velocity of the individual $\operatorname{drop}(\mathrm{m} / \mathrm{s})$

$V_{d} \quad$ superficial dispersed phase velocity $(\mathrm{m} / \mathrm{s})$

We Weber number $\left(\Delta \rho \mathrm{d}_{\mathrm{N}} \mathrm{u}_{\mathrm{n}}{ }^{2} / \sigma\right)$

$\mathrm{Z} \quad$ plate spacing $(\mathrm{m})$

\section{Greek Letters}

$\Delta \rho \quad$ density difference $\left(\mathrm{kg} / \mathrm{m}^{3}\right)$

$\varepsilon_{d} \quad$ dispersed phase dynamic hold up

$\varepsilon_{s} \quad$ dispersed phase static hold up

$\varepsilon_{t} \quad$ dispersed phase total hold up

$\mu \quad$ viscosity of the phases ( $\mathrm{Pa} \mathrm{s}$ ) 
$\rho \quad$ density of the phases $\left(\mathrm{kg} / \mathrm{m}^{3}\right)$

$\sigma \quad$ surface/interfacial tension $(\mathrm{N} / \mathrm{m})$

i number of plates

\section{Subscripts}

$c \quad$ continuous phase

$d \quad$ dispersed phase

$i \quad$ number of plates

\section{REFERENCES}

Bhavasar, P. M., Jafarabad, K. R., Pandit, A. B., Sawant, S. B. and Joshi, J. B., Drop volumes and terminal velocities in aqueous two phase systems. Can. J. Chem. Eng., 74, 852-860 (1996).

Bhawsar, P. M., Pandit, A. B., Sawant, S. B., Joshi, J. B., Enzyme mass transfer coefficient in a sieve plate extraction column. Chem. Eng. J., 55, B1-B17 (1994).

Brady, C., Metcalfe, L., Slaboszewski, D., Frank, D., Lipase immobilized on a hydrophobic, microporous support for the hydrolysis of fat. J. Am. Oil. Chem. Soc., 65, 917-921 (1998).

Dhondge, A. S., Rathod, V. K., Hydrodynamics of spray column for enzymatic reactions of oil. Chem. Eng. Res. Des., 90(7), 870-876 (2012).

Hamidi, A., van Berlo, M., Luyben, K. Ch. A. M., van der Wielen, L. A. M., Flooding characteristics of aqueous two-phase systems in a countercurrent sieve-plate column. J. Chem. Technol. Biotechnol., 74(3), 244-249 (1999).

Igarashi, L., Kieckbusch, T. G., Franco, T. T., Xylanase mass transfer studies in aqueous two-phase systems using spray and sieve plate columns. Bioprocess Biosyst. Eng., 26(3), 151-157 (2004).

Kimura, Y., Tanaka, A., Sonomoto, T., Nihira, T., Fukui, S., Applications of immobilized lipase to hydrolysis of triacylglyceride. Eur. J. Appl. Microbial. Biotechnol., 17, 107-112 (1983).
Krishnamurthy, R., Jagannadha Rao, R., Venkat Rao, C., Effect of hole diameter on mass transfer rates in perforated plate extraction towers: Pegasolebutyric acid-water system. Indian J. Technol., 5, 271-275 (1967).

Laddha, G. S., Kirshnan, T. R., Vishwanathan, S., Vedian, S., Degalessan, T. E., Hoelscher, H. E., Some performance characteristics of liquid phase spray columns. AIChE J., 22, 456-459 (1976).

Lodh, B. B., Raja Rao, M., Mass transfer efficiency in perforated plate extraction towers. Indian $\mathrm{J}$. Technol., 4, 163-166 (1966).

Mayfield, F. D., Church, W. L., Liquid-liquid extractor design. Ind. Eng. Chem., 44, 2253 (1952).

Muthuravichandran, B., Degaleesan, T. E., Laddha, G. S., Hydrodynamics and mass transport in sieveplate extraction columns. Indian J. Technol., 27(3), 125-139 (1989).

Posorske, L. H., Lefebvre, G. K., Miller, C. A., Hansen, T. T., Glenvig, B. L., Process consideration of continuous fat modification with an immobilized lipase. J. Am. Oil. Chem. Soc., 65, 922-926 (1988).

Puthli, M. S., Rathod, V. K., Pandit, A. B., Enzymatic hydrolysis of castor oil: Process intensification studies. Biochem. Eng. J., 31(1), 31-41 (2006).

Rathod, V. K., Pandit, A. B., Enzymatic hydrolysis of oil in a spray column. J. Mol. Catal. B, Enzym., 67 (1-2), 1-9 (2010).

Rathod, V. K., Pandit, A. B., Effect of various additives on enzymatic hydrolysis of castor oil. Biochem. Eng. J., 47(1-3), 93-99 (2009).

Rocha, J. A., Humphrey, J. L., Fair, J. R., Mass transfer efficiency of sieve tray extractors. Ind. Eng. Chem. Process. Des. Dev., 25, 862 (1986).

Treybal, R. E., Mass Transfer Operation. McGraw Hill, New York, pp. 477-541 (1980).

Van der Padt, A., Sewalt, J. J. W., Agoston, S. M. I., Van't Riet, K., Candida rugosa lipase stability during acylglycrol synthesis. Enzyme Microb. Tech., 14, 805-812 (1992). 